\title{
TEORIA E PRÁTICA NA FORMAÇÃO DE PROFESSORES NO CURSO DE PEDAGOGIA: perspectivas e limites da extensão universitária
}

Andréa Kochhann ${ }^{1}$

\section{INTRODUÇÃO}

O objeto da pesquisa é a formação de professores, especificamente a formação da pedagoga e do pedagogo. Delimita-se em investigar a formação do pedagogo levando em consideração a relação teoria e prática, pelas vias da extensão universitária, na Universidade Estadual de Goiás, no período de 2016 a 2018.

O objeto será investigado no doutorado que pertence à linha "Profissão docente, currículo e avaliação" da Pós-Graduação Strictu Senso da Universidade de Brasília e pertence ao GEFPAFE- Grupo de Estudos e Pesquisa sobre Formação e Atuação de Professores/Pedagogos e ao GEFOPI - Grupo de Estudos em Formação de Professores e Interdisciplinaridade. Vincula-se a esta pesquisa outras pesquisas de graduação e pós-graduação da UEG - Universidade Estadual de Goiás.

A configuração do problema se estrutura no seguinte questionamento "Quais as perspectivas e os limites da relação teoria e prática na formação de professores do Curso de Pedagogia pela extensão universitária?". Portanto, analisar-se-á a concepção e política da Universidade em relação ao processo de formação do pedagogo com base na prática da extensão universitária.

\section{METODOLOGIA}

\footnotetext{
${ }^{1}$ Docente Efetiva da Universidade Estadual de Goiás - UEG. Pedagoga pela UEG. Mestre em Educação pela Pontifícia Católica de Goiás. Doutoranda em Educação pela Universidade de Brasília. Pesquisadora e Extensionista. andreakochhann@yahoo.com.br
} 
Esta pesquisa qualitativa se configura enquanto bibliográfica e empírica. Enquanto bibliográfica terá como corpus teórico a concepção de Gramsci (1979, 1991, 1995, 2000, 2010) e Marx (1979, 1987) sobre emancipação e práxis, tendo contribuição de autores como Vazquez (1968), Saviani $(2000,2007)$ e Silva $(2011,2015)$ e; em Saviani $(2006,2008,2009)$ sobre a universidade brasileira e o curso de Pedagogia.

A pesquisa seguirá a perspectiva crítico-emancipadora de Silva (2008, 2015) e histórico-crítico-dialético de Saviani (2008) se apresentam como procedimentos metodológicos e tendências educacionais. Os instrumentos de coleta de dados serão análise documental da UEG, mapeando as ações de extensão em execução dos Câmpus, analisando os resumos e projetos, analisando os relatórios mensais e final das ações, bem como os produtos acadêmicos-científicos, dispostos na Plataforma Pégasus, da UEG.

Realizar-se-á entrevista semiestruturada com os professores proponentes das ações e alunas(os) que participam destas ações. Haverá observação não participante, com diário de bordo, de ações extensionistas, escolhidas intencionalmente, mediante avaliação de descritores que configurem a práxis favorecendo a formação acadêmica.

A média de ações extensionistas da UEG, por ano, é de 450, conforme dados www.pre.urg.br. Deste total, uma média de 300 ações são de projetos de extensão. Um percentual de 200 ações são da Educação e destas, em 2015, 41 eram do curso de Pedagogia. Estima-se uma avaliação de 200 projetos de extensão ao longo da pesquisa.

\section{RESULTADOS E DISCUSSÃO}

A universidade brasileira enquanto espaço por excelência da pesquisa, conforme afirma Demo (2006) e como o Manifesto dos Pioneiros da Educação já apresentava em 1932 e, reforçado em 1959, se estabelece no ensino e na extensão. Para Demo (2006) a pesquisa somente tem sentido se revertido em ensino e em extensão. Caso contrário, é inócua.

A historicidade das universidades brasileiras apresenta que a extensão universitária por muitos anos ficou fora do cenário. Apenas na década de 1960 com a ousadia de Paulo Freire, as ações extensionistas aparecem 
como algo que pode gerar frutos. Mas, com a ditadura militar, Freire e suas ações extensionistas foram exiladas do Brasil, por representarem ameaça a sociedade. Somente no período de redemocratização, a extensão universitária, volta a ser discutida.

Apesar dessa intenção, a pesquisa que originou este trabalho, se encontra em fase inicial, mas já pode inferir que um dos grandes entraves da extensão universitária é o entendimento de seus conceitos e sentido de ser. Os agentes universitários precisam compreender o que vem a ser a extensão universitária e qual seu sentido de ser para uma universidade e sociedade. Para fazer extensão é preciso intencionalidade. Extensão não se faz a solavancos.

Para o FORPROEXT (2007, p. 17) é "A Extensão Universitária é o processo educativo, cultural e científico que articula o Ensino e a Pesquisa de forma indissociável e viabiliza a relação transformadora entre a Universidade e a Sociedade.". Existem algumas interpretações para esse conceito. Uma delas é que a extensão universitária é uma atividade prática. Outra é que é um retorno a sociedade daquilo adquirido pela universidade. É preciso compreender a prática e o retorno.

A abrangência conceitual da extensão universitária extrapola as barreiras disciplinares e os muros da universidade. Portanto, deveria ser entendida como o elemento constitutivo mais importante do tripé universitário. Enquanto prática a extensão universitária é deveria ser uma práxis, pois a teoria advinda da pesquisa fundamenta as ações extensionistas. Enquanto retorno é importante saber que os ganhos são para os dois lados, mas, é a sociedade quem deve dar o norte para a universidade atuar na extensão universitária. A universidade precisa buscar na sociedade os problemas que emergem e no âmbito da pesquisa buscar compreender os motivos do problema e ao encontrar a solução, devolver à sociedade por meio de ações extensionistas.

Nesse processo ganha a sociedade ao ter seus problemas compreendidos e resolvidos e ganha 0 acadêmico com o processo de amadurecimento das práticas pedagógicas, vindas da pesquisa e da extensão. Sobre o processo de indissociabilidade entre a pesquisa, o ensino e a extensão, Celeste (2014, p. 5) 
Propõe uma visão radical em relação à indissociabilidade. A extensão se faz dentro e com pesquisa e ensino, assim suas ações aparecem dentro dos currículos e nos projetos de pesquisa e pós-graduação, propondo até mesmo que as pró-reitorias de extensão sejam fundidas com pesquisa e ensino. A extensão é necessária para o ensino e a pesquisa cumprirem seus papéis inseridos na realidade da comunidade local $[\ldots]$

Esse amadurecimento acadêmico advindo da indisssociabilidade, vem de encontro com uma das diretrizes da extensão universitária que é apresentado pelo FORPROEXT (2007), tais sejam: a interação dialógica, interdisciplinaridade e interprofissionalidade, indissociabilidade ensinopesquisa-extensão, impacto na formação do estudante e, finalmente, impacto e transformação social.

O impacto na formação do estudante deve ser levado em consideração ao pensar uma ação extensionista. Muitas universidades levam em consideração a extensão como uma forma de ser reconhecida na sociedade. Não basta isso. É preciso entender a extensão universitária como uma forma de produção de conhecimento e de formação intelectual e didáticometodológica do estudante.

A extensão universitária não pode ser vista como uma parte meramente prática da universidade. Ela é envolta de intensidade teórica, advinda da pesquisa ou que propicia a pesquisa. A motivação pela investigação no tocante a articulação teoria e prática surge por consequência das considerações de Machado (2013) sobre o curso de Pedagogia na UEG, quanto ao seu desenvolvimento curricular, constando potencialidades $\mathrm{e}$ fragilidades, apontando pouca pesquisa, extensão e monitoria e o projeto pedagógico aponta a práxis como princípio fundante do curso.

Discutir o conceito de práxis com autores evidentemente filiados ao marxismo se torna necessário neste momento. Para Gramsci (2010, p. 33) a escola e os projetos pedagógicos devem ser modificados para atender a formação visando a emancipação, assim, "Trata-se, porém, de inovar os métodos, os conteúdos e a organização do estudo com base nas seguintes advertências: uma vinculação mais estreita entre a escola e o trabalho, entre a teoria e a prática; [...]". Silva (2011) assevera que é importante distinguir que, 
como afirma Vazquez (1968) nem toda atividade prática pode ser considerada práxis, mas toda práxis é uma prática.

A análise investigativa da relação teoria e prática pelo viés da extensão universitária deve-se a alguns fatores. A extensão é uma práxis quando entendida como uma ação transformadora, com bases sólidas, tanto teóricas quanto metodológicas, visando a emancipação do ser humano. Uma universidade que visa cumprir com seu papel social para além da produção do conhecimento, pela pesquisa, realiza a socialização de suas elaborações, por meio das ações de extensão.

As contribuições da extensão universitária para a formação dos acadêmicos têm sido discutidas em congressos e explicitadas em documentos e livros, como na Política Nacional de Extensão Universitária, em que a UEG se embasa para elaborar as suas diretrizes. A extensão não pode ser vista apenas como as ações que visam à transformação social. Mas, também a transformação acadêmica.

As ações extensionistas são planejadas, acompanhadas, executadas e avaliadas por um professor orientador, além das produções científicas que produzem. Dessa forma, uma ação extensionista transforma a sociedade em que a ação é realizada, mas, também o acadêmico enquanto age nessa sociedade. Para que isso ocorra é imprescindível que as universidades promovam debates sobre as concepções e o sentido de ser da extensão universitária.

É preciso que os docentes compreendam que a extensão universitária passa pelo ensino e pela pesquisa, ou seja, se faz com o domínio teórico e metodológico, pois é intencional. A universidade criou uma concepção de que a pesquisa é a sua essência e com isso menosprezou a extensão. Está na hora de entender que a pesquisa não tem sentido se for colocada a serviço da sociedade. Eis o trabalho da extensão universitária e um valioso momento para a formação do estudante, por meio da práxis acadêmica. Assim, é preciso compreender também as concepções de práxis, enquanto uma relação indissolúvel entre a teoria e a prática.

\section{CONSIDERAÇÕES FINAIS}


A extensão se define como um vasto conjunto de ações e grande demanda de possibilidades de formação acadêmica. $E$ realizada principalmente, através de projetos, podendo se expressar por publicações. A extensão é uma forma de divulgar a conclusão do que foi pesquisado e ensinado. Sendo um processo educativo, científico e articulado deve ser bem planejado, com base teórica e com a prática metodológica, ou seja, a práxis.

A extensão não é prática por prática. A extensão é a prática teorizada. Para Demo (2006) a extensão deve ser originada da pesquisa ou vice-versa. Assim, a extensão é uma ação em que a indissociabilidade teoria e prática acontecem. $\mathrm{O}$ acadêmico que realizar ações extensionistas terá uma experiência de práxis acadêmica. Isso contribuirá para sua formação e atuação.

Como nossa pesquisa está em sua fase inicial, em que predominam as leituras e compreensão teórica, almejamos escrever outros artigos para elucidar o questionamento central "Quais as perspectivas e os limites da relação teoria e prática na formação de professores do Curso de Pedagogia pela extensão universitária?".

\section{REFERÊNCIAS}

GRAMSCI, A. Cadernos do cárcere. Edição e tradução: Carlos Nelson Coutinho. Rio de Janeiro: Civilização Brasileira, 2000.

GRAMSCI, A. Concepção dialética da História. Tradução de Carlos Nelson Coutinho. 10. ed. Rio de Janeiro: Ed. Civilização Brasileira, 1995.

GRAMSCI, A. CADERNO 12 - Documento Especial In: História \& perspectivas n.5. Uberlândia, 1991.

GRAMSCI, A. Os intelectuais e a organização da cultura. RJ: Civilização Brasileira, 1979.

MARX, K. Manuscritos econômicos e filosóficos. Coleção Os pensadores. São Paulo: Nova Cultura, 1987. 
MARX, K. Sobre a questão judaica. São Paulo: Boitempo, 2010.In: file:///C:/Users/andrea/Downloads/17295-92977-1-PB.pdf.

MARX, K. Salário, preço e lucro. Trad. Paulo Ferreira Leite. 4 ed. São Paulo: Centauro, 2002.

MARX, K. O capital: Crítica da economia política. Rio de Janeiro: Bertand Brasil, 1979.

MARX, K e ENGELS, F. A ideologia alemã: Teses sobre Feurbach. São Paulo: Moraes, 1984.

MARX, K. e ENGELS, F. Manifesto do Partido Comunista. São Paulo: Cortez, 1998.

MÉSZÁROS, István. A Educação para além do capital. 2.ed. São Paulo: Boitempo, 2008.

MONASTA, Atílio. Antonio Gramsci .Tradução: Paolo Nosella. Recife: Fundação Joaquim Nabuco, Massangana, 2010. MOREIRA, M.A. Aprendizagem significativa: a teoria e textos complementares. São Paulo, Livraria Editora da Física, 2010.

NAGEL, Lízia Helena. A sociedade do conhecimento no conhecimento dos educadores. Texto aprovado e publicado nos Anais (em CD-ROM) do I Seminário Internacional de Educação. Cianorte: 2001. [Arquivo: SOCIEDconhecim]

RODRIGUES, Alberto Tosi. Sociologia da Educação. 6.ed. Rio de Janeiro: Lamparina, 2007.

SAVIANI, D. Formação de professores: aspectos históricos e teóricos do problema no contexto brasileiro. REVISTA BRASILEIRA DE $\begin{array}{lllll}\text { EDUCAÇÃO.Vol. } 14 . & \text { N.40 Jan/Abril. } 2009 . & \text { In: }\end{array}$ http://www.scielo.br/pdf/rbedu/v14n40/v14n40a12.pdf

SAVIANI. D. Sistema Nacional de Educação: O lugar da educação superior. educAtiva, Goiânia, v. 13, n. 1, p. 45-66, jan;jun. 2010http://seer.ucg.br/index.php/educativa

SAVIANI, D. Educação socialista, pedagogia histórico-crítica e os desafios da sociedade de classes. In: LOMBARDI, José Claudinei e SAVIANI, Demerval (orgs.). 2. ed. Marxismo e educação: Debates contemporâneos. Campinas: São Paulo: Autores Associados, 2008b.

SILVA, K.A.C.P.C. A formação de professores na perspectiva críticoemancipadora. Linhas Críticas, Brasília, DF, v. 17, n. 32, p. 13-31, jan./abr. 2011. 
Fontes Financiadoras - Universidade Estadual de Goiás com bolsa Monitoria, bolsa Pro-licenciatura, bolsa Permanência, bolsa PIBID, bolsa Extensão, bolsa PIBIC, bolsa FAPEG, bolsa CNPQ e apoio financeiro a eventos com o Edital Pró-Eventos. E ao GEPFAPE - Grupo de Estudos e Pesquisa em Formação e Atuação de Professores/Pedagogos da Universidade de Brasília. 